\title{
Impact of Magnesium Source on the Yield and Structure of struvite
}

\author{
E. Fosso-Kankeu, T. Netshidzivhe, E. Mamakoa, V. Masindi and HWJP. Neomagus
}

\begin{abstract}
Magnesium ammonium phosphate, also known as struvite, is a salt that forms spontaneously in water that contains equimolar ratios of its components - phosphates, magnesium and ammonia. Recently, researchers have studied struvite precipitation with an intention to recover phosphorus. Wastewater has been identified as a suitable source to synthesize struvite to recover phosphorus instead of discarding it to surface water bodies in large quantities. Municipal wastewater is rich in phosphorus and toxic nutrients like ammonia which negatively impact the environment and pollute natural water sources. Struvite synthesis provides an opportunity to beneficiate wastewater and then removed ammonia and phosphate can be used as a slow-release fertilizer. The drawback of using wastewater is that magnesium is usually the limiting ion and it must be added as a precursor to allow for struvite precipitation. Various magnesium sources have been used in previous studies and compared based on the quality of the struvite they form, cost, availability, morphology and the yield of struvite. This study focused on the use of magnesium oxide $(\mathrm{MgO})$ and calcined magnesite $\left(\mathrm{MgCO}_{3}\right)$ as magnesium sources to precipitate struvite. . Experimental results showed that $\mathrm{MgCO}_{3}$ had a greater precipitate yield than $\mathrm{MgO}, \mathrm{MgO}$ had a higher phosphorus recovery and the ammonia recovery was approximately equal to that of $\mathrm{MgCO}_{3}$
\end{abstract}

Keywords - Struvite, Wastewater, Magnesium, Phosphorus

\section{INTRODUCTION}

The recovery of struvite $\left(\mathrm{MgNH}_{4} \mathrm{PO}_{4} \cdot 6 \mathrm{H}_{2} \mathrm{O}\right)$ is quite an established activity because it has been identified as a feasible method to recover phosphorus from wastewater. Laboratory scale experiments have been conducted on struvite precipitation for various research topics and wastewater sources. Municipal wastewater has been reported as the source of significant amounts of phosphorus [1]. The removal of ammonia from wastewater through struvite precipitation has been explored by researchers and proven as efficient. Ammonia-nitrogen is removed from water using air stripping, biological nitrification-denitrification, breakpoint chlorination, ion exchange or chemical precipitation [1][3]. The removal of both phosphorus and ammonia from wastewater limits their

Manuscript received October 5, 2020

E. Fosso-Kankeu is with the Water Pollution, Monitoring and Remediation Initiatives Research Group and the School of Chemical and Minerals Engineering, North-West University, Potchefstroom campus, South Africa.

T. Netshidzivhe and M.E Mamakoa are with the Water Pollution and Monitoring Initiatives Group, School of Chemical and Minerals Engineering at North-west University, Potchefstroom, South Africa.

V Masindi is with the Department of Environmental Sciences, School of Agriculture and Environmental Sciences, University of South Africa.

HWJP Neomagus is with the School of Chemical and Minerals Engineering at North-west University, Potchefstroom, South Africa. environmental impact; they promote eutrophication on surface water bodies which in turn affects water quality and all aquatic living organisms [4] and [5]. Struvite precipitation serves the purpose of recovering these nutrients for reuse and protecting the aquatic environment from pollution. Struvite can be used as an alternative fertilizer because of the high nutrient recovery efficiency from its precipitation and its slow nutrient release characteristics into the soil [3]. The reuse of phosphorus is beneficial because it is a finite resource, the phosphate rock is approaching possible depletion in the world; therefore the use of struvite as fertilizer has the potential to close the open phosphorus cycle and reduce the rate of phosphate rock mining [1], [6] and [7].

For struvite precipitation to occur, the molar ratio between magnesium, phosphate and ammonia $\left(\mathrm{Mg}: \mathrm{PO}_{4}: \mathrm{NH}_{4}\right)$ in the wastewater needs to be 1:1:1 but magnesium is usually the limiting ion in the water [8]. The reaction is dependent on the $\mathrm{Mg}: \mathrm{P}: \mathrm{NH}_{4}$ molar ratio, temperature, mixing energy, reaction time and $\mathrm{pH}$. A magnesium source needs to be added to the wastewater as a precursor to increase the magnesium concentration and allow for an equimolar stoichiometric ratio between the ions for struvite precipitation. Struvite precipitation is spontaneous, with an optimal temperature range of $15^{\circ} \mathrm{C}-35^{\circ} \mathrm{C}$ and an alkaline $\mathrm{pH}$ range of $9-10.5$ has been reported as optimal [1] and [3]. The reaction is affected by the presence of foreign ions, the co-precipitation of other compounds with struvite affect its purity, quality and yield.

Research has recently shifted on finding alternative magnesium sources to use for struvite precipitation. The use of commercial magnesium salts is costly and this has contributed to the slow development of struvite precipitation at large scale. The use of affordable, energy-efficient and easily accessible magnesium sources has been explored by many researchers and their experiments were successful but with a few disadvantages. These alternatives included desalination brine, seawater, wood ash, bittern and by-product magnesite [2], [6] and Error! Reference source not found. The main disadvantage is the presence of competing ions in these magnesium sources. A Feedstock Sustainability Index was developed by [1] and it ranks wastewater sources according to their suitability for struvite precipitation. Fertilizer industry wastewater, cochineal insects processing wastewater, human urine and landfill leachate were ranked higher than municipal wastewater. For industrial scale, the use of these top-ranked wastewater sources will be efficient if the target is to maximize struvite yield and nutrient recovery.

Most of the studies have used $\mathrm{MgCl} 2$ as the source of magnesium $[5,6]$ for the precipitation of struvite from 
wastewater; however, our previous review [7] reported that the source pf magnesium could influence the properties of struvite. This study aims to compare struvite produced from two sources of magnesium, $\mathrm{MgO}$ and $\mathrm{MgCO}_{3}$, the comparison is based on the quality of struvite and the yield obtained from each magnesium source.

\section{MATERIALS AND METHODS}

\section{A. Sampling}

Wastewater was collected from Zeekoegat wastewater treatment works in Pretoria, South Africa (253' $15^{\prime \prime} \mathrm{S}$ $\left.28^{\circ} 20^{\prime} 05^{\prime \prime} \mathrm{E}\right)$. The water was collected from a digester's supernatant liquid known to have significant concentration levels of ammonia and phosphates. The constituents of the sewage wastewater were determined and are presented in Table I and Table II.

\section{B. Chemicals and reagents}

Two different magnesium sources were used as precursors for struvite synthesis, namely, magnesium oxide $(\mathrm{MgO})$ and calcined magnesite $\left(\mathrm{MgCO}_{3}\right)$. $(\mathrm{MgO})$ was purchased from Associated chemical enterprises, South Africa and it was used as an analytical grade, the calcined cryptocrystalline magnesite is a local magnesium source and it was used without any further treatment.

\section{Experimental procedure}

Suspended solids in the wastewater were filtered using 150 $\mathrm{mm}$ ashless filter paper. Batch experiments were conducted at lab-scale and at varied $\mathrm{Mg} / \mathrm{P}$ molar ratios in triplicates. Temperature range, $\mathrm{pH}$ range, mixing energy and mixing time were kept constant. The $\mathrm{Mg} / \mathrm{P}$ ratios studied were $1: 1$ and 1.2:1, temperature range of the wastewater was kept between $21^{\circ} \mathrm{C}$ $25^{\circ} \mathrm{C}$ and the $\mathrm{pH}$ range was $10: 00-10.50 .500 \mathrm{~mL}$ of the filtered raw sample was used for every run in $1 \mathrm{~L}$ beakers, the experiments were conducted in triplicates for each magnesium source at the two different $\mathrm{Mg} / \mathrm{P}$ ratios. Magnetic stirrers were used to mix the solutions for 30 minutes and the beakers were sealed with parafilm. The residence time was varied for some of the runs to test the relationship between residence time and yield. Residence times of 3 hours, 18 hours and 48 hours were used. The crystals formed were filtered and collected through vacuum filtration (through the $150 \mathrm{~mm}$ ashless filter paper) and dried in an oven overnight at $38^{\circ} \mathrm{C}$. The residual water from each run was filtered through $0.45 \mu \mathrm{m}$ syringe filters before they were sent for analysis. The initial $\mathrm{pH}$ of the raw wastewater was 7.10 .

\section{Dosage}

Equation (1) was used to calculate the percentage of magnesium available in each of the magnesium sources to ensure that the right amount of magnesium (in grams) was added to the wastewater for struvite precipitation to take place.

\section{Percentage composition by mass}

$$
\begin{aligned}
& =\frac{\text { molar mass of element } \times N}{\text { molar mass of compound }} \\
& \times 100
\end{aligned}
$$

Where $\mathrm{N}$ is the number of that element in the compound.

The data in Table I was used to calculate the suitable magnesium dosage to achieve the $\mathrm{Mg} / \mathrm{P}$ ratio of $1: 1$ for the first run of experiments and 1.2:1 for the second run of experiments.

\section{ANALYTICAL METHODS}

The ion concentrations of $\mathrm{PO}_{4}{ }^{3-}, \mathrm{NH}_{4}$ in the raw water sample were analyzed by ion chromatography (IC) Metrohm make - Compact 930 AnCat Flex IC Chromatograph, and the $\mathrm{Mg}$ ions and other metals were analyzed using an inductively coupled plasma-optical emission spectrometry (ICP-OES) Agilent make - ICP OES 725. The residual water was analyzed to determine the concentration of the remaining ions in the water after struvite precipitation. The dried crystals were measured on a bench scale to determine the yield in grams.

TABLE I: IC RAW WASTEWATER CONSTITUENTS IN MG/L

\begin{tabular}{cc}
\hline \hline Component $(\mathrm{mg} / \mathrm{L})$ & IC result \\
\hline $\mathrm{PO}_{4}{ }^{3-}$ & 543.217 \\
$\mathrm{NH}_{4}{ }^{+}$ & 559.114 \\
$\mathrm{Cl}^{-}$ & 76.009 \\
$\mathrm{SO}_{4}{ }^{2-}$ & 30.530 \\
$\mathrm{Na}^{+}$ & 70.938 \\
$\mathrm{~K}^{+}$ & 82.651 \\
$\mathrm{NO}_{3}{ }^{-}$ & 7.545 \\
\hline
\end{tabular}

TABLE II: ICP RAW WASTEWATER CONSTITUENTS IN MG/L

\begin{tabular}{cc}
\hline \hline Component $(\mathrm{mg} / \mathrm{L})$ & ICP result \\
\hline $\mathrm{Mg}^{2+}$ & 48.305 \\
$\mathrm{Ca}^{2+}$ & 44.799 \\
$\mathrm{Na}^{+}$ & 64.804 \\
$\mathrm{~K}^{+}$ & 82.527 \\
\hline
\end{tabular}

\section{RESULTS AND DISCUSSION}

\section{A. Yield}

The dry struvite crystals from each run were measured separately and the yield results are given in Table III and Table IV. The yield of the synthesized struvite (in grams) increased with the magnesium source dosage. Residence time of 48 hours and less did not have an impact on the yield of struvite, there was no significant difference in mass when residence time was 3 hours, 18 hours and when it was changed to 48 hours.

TABLE III: YIELD OF STRUVITE CRYSTALS AT 1:1 MG/P RATIO

\begin{tabular}{cccc}
$\begin{array}{c}\text { Magnesium } \\
\text { source }\end{array}$ & Run 1 (g) & Run 2 (g) & Run 3 (g) \\
\hline $\begin{array}{c}\mathrm{MgO} \\
\mathrm{MgCO}_{3}\end{array}$ & 1.692 & 1.659 & 1.632 \\
\hline
\end{tabular}


TABLE IV: YIELD OF STRUVITE CRYSTALS AT 1.2:1 MG/P RATIO

\begin{tabular}{cccc}
\hline \hline $\begin{array}{c}\text { Magnesium } \\
\text { source }(\mathrm{g})\end{array}$ & Run 1 $(\mathrm{g})$ & Run 2 $(\mathrm{g})$ & Run 3 $(\mathrm{g})$ \\
\hline $\mathrm{MgO}$ & 1.741 & 1.728 & 1.756 \\
$\mathrm{MgCO}_{3}$ & 2.852 & 2.875 & 2.884 \\
\hline
\end{tabular}

\section{B. Efficiency of Phosphorus and ammonia recovery}

Phosphorus and ammonia recoveries were calculated using Equation (2).

$$
\begin{aligned}
& \text { Nutrient recovery } \\
& =\left(\frac{X_{\text {initial }}-X_{\text {final }}}{X_{\text {initial }}}\right) \\
& \times 100 \%
\end{aligned}
$$

Where $\mathrm{X}$ is the nutrient in $\mathrm{mg} / \mathrm{L}$.

The IC report of the residual water indicates that $99.7 \%$ of the $\mathrm{PO}_{4}{ }^{3-}$ was removed from the raw water when $\mathrm{MgCO}_{3}$ was used as a pre-cursor at a $\mathrm{Mg} / \mathrm{P}$ ratio of $1: 1$. When the $\mathrm{Mg} / \mathrm{P}$ ratio was increased to $1.2: 1$, the percentage removal was $98.5 \%$, indicating that the equimolar ratio was optimal for the calcined magnesite magnesium source. The removal of ammonia was $83.4 \%$ at a $\mathrm{Mg} / \mathrm{P}$ ratio of $1: 1$ and it increased to $89.9 \%$ when the $\mathrm{Mg} / \mathrm{P}$ was increased to $1.2: 1$. The $\mathrm{pH}$ was kept at 10.00 throughout the reactions.

The calcined magnesite is a good magnesium source for nutrient recovery, it also provided the highest yield compared to $\mathrm{MgO}$. It can thus be used to clean wastewater from these nutrients to prevent eutrophication. In both cases, the phosphorus and ammonia recovery is very high and this is favorable if the struvite is to be used as a slow release fertilizer. The IC results of the residual water (at $\mathrm{Mg} / \mathrm{P}$ ratio of $1: 1$ ) are presented in Table V. Table VI presents the results at $\mathrm{Mg} / \mathrm{P}$ ratio of 1.2:1. All data were considered acceptable because the standard deviation of the samples is less than $10 \%$.

TABLE V: $1: 1$ - IC RESIDUAL WASTEWATER RESULTS IN MG/L FOR $\mathrm{MGCO}_{3}$

\begin{tabular}{cccc}
\hline $\begin{array}{c}\text { Component } \\
(\mathrm{mg} / \mathrm{L})\end{array}$ & Run 1 & Run 2 & Run 3 \\
\hline $\mathrm{Mg}^{2+}$ & 109.337 & 141.753 & 120.401 \\
$\mathrm{PO}_{4}{ }^{3-}$ & 1.310 & 1.608 & - \\
$\mathrm{NH}_{4}{ }^{+}$ & 76.298 & 96.078 & 94.111 \\
$\mathrm{SO}_{4}{ }^{2-}$ & 34.480 & 36.217 & 36.543 \\
$\mathrm{Na}^{+}$ & 137.753 & 137.867 & 116.752 \\
$\mathrm{Ca}^{2+}$ & 17.658 & 13.833 & 21.472
\end{tabular}

-: Not detected
TABLE VI: 1.2:1 - IC RESIDUAL WASTEWATER RESULTS IN MG/L FOR $\mathrm{MGCO}_{3}$

\begin{tabular}{cccc}
\hline \hline $\begin{array}{c}\text { Component } \\
(\mathrm{mg} / \mathrm{L})\end{array}$ & Run 1 & Run 2 & Run 3 \\
\hline $\mathrm{Mg}^{2+}$ & 123.780 & 146.520 & 130.760 \\
$\mathrm{PO}_{4}^{3-}$ & 5.980 & 10.920 & 6.820 \\
$\mathrm{NH}_{4}{ }^{+}$ & 59.390 & 54.820 & 55.080 \\
$\mathrm{SO}_{4}{ }^{2-}$ & 40.510 & 38.420 & 34.330 \\
$\mathrm{Na}^{+}$ & 61.250 & 64.460 & 58.780 \\
$\mathrm{~K}^{+}$ & 75.060 & 78.510 & 76.48 \\
$\mathrm{Ca}^{2+}$ & 14.850 & 24.700 & 23.980 \\
$\mathrm{NO}_{3}{ }^{-}$ & 20.440 & 14.790 & 11.710 \\
\hline
\end{tabular}

All the $\mathrm{PO}_{4}{ }^{3-}$ was successfully removed from the raw water when $\mathrm{MgO}$ was used at a $\mathrm{Mg} / \mathrm{P}$ ratio of $1: 1$. When the $\mathrm{Mg} / \mathrm{P}$ ratio was increased to $1.2: 1$, the percentage $\mathrm{PO}_{4}{ }^{3-}$ removal was $98.8 \%$ and this indicates that the equimolar ratio was optimal for a $\mathrm{MgO}$ pre-cursor. The addition of $\mathrm{MgO}$ into the wastewater increased the $\mathrm{pH}$ from 7.10 to approximately 10.50 and it was observed that dosage does affect $\mathrm{pH}$ because when the $\mathrm{Mg} / \mathrm{P}$ ratio was increased, the $\mathrm{pH}$ increased to 10.80 . This increase in $\mathrm{pH}$ might be the reason why the recovery of $\mathrm{PO}_{4}{ }^{3-}$ decreased by $1.2 \% . \mathrm{A} \mathrm{PO}_{4}{ }^{3-}$ recovery of $98.8 \%$ is still high and the struvite crystals are eligible to be reused.

At a $\mathrm{Mg} / \mathrm{P}$ ratio of $1: 1,83.9 \%$ ammonia was removed and it increased to $89.5 \%$ when the $\mathrm{Mg} / \mathrm{P}$ ratio was increased to $1.2: 1$.

It is observed that for both magnesium sources, an increase of their dosage increases the ammonia removal, the phosphorus removal decreases but the effect is not very significant. Both recoveries at a $\mathrm{Mg} / \mathrm{P}$ ratio of $1.2: 1, \mathrm{pH}$ between 10 and 10.80 , temperature of $24^{\circ} \mathrm{C}$ and a mixing time of 30 minutes were viable. Residence time did not affect nutrient recovery.

The IC results of the $\mathrm{MgO}$ residual water (at $\mathrm{Mg} / \mathrm{P}$ ratio of 1:1) are presented in Table VII and Table VIII presents the results at $\mathrm{Mg} / \mathrm{P}$ ratio of 1.2:1.

All data were considered acceptable because the standard deviation of the samples is less than $10 \%$.

TABLE VII: 1:1 - IC RESIDUAL WASTEWATER RESULTS IN MG/L FOR MGO

\begin{tabular}{cccc}
\hline $\begin{array}{c}\text { Component } \\
(\mathrm{mg} / \mathrm{L})\end{array}$ & Run 1 & Run 2 & Run 3 \\
\hline $\mathrm{Mg}^{2+}$ & 192.690 & 192.690 & 192.643 \\
$\mathrm{PO}_{4}{ }^{3-}$ & - & - & - \\
$\mathrm{NH}_{4}{ }^{+}$ & 96.964 & 96.964 & 76.594 \\
$\mathrm{Cl}^{-}$ & 79.471 & 79.471 & 79.842 \\
$\mathrm{SO}_{4}{ }^{2-}$ & 33.842 & 33.613 & 33.931 \\
$\mathrm{Na}^{+}$ & 73.318 & 67.172 & 74.719 \\
$\mathrm{~K}^{+}$ & 80.779 & 80.779 & 75.177 \\
$\mathrm{Ca}^{2+}$ & 11.028 & 11.154 & 14.952
\end{tabular}

-: Not detected 
TABLE VIII: 1.2:1 - IC RESIDUAL WASTEWATER RESULTS IN MG/L FOR MGO

\begin{tabular}{cccc}
\hline \hline $\begin{array}{c}\text { Component } \\
(\mathrm{mg} / \mathrm{L})\end{array}$ & Run 1 & Run 2 & Run 3 \\
\hline $\mathrm{Mg}^{2+}$ & 176.55 & 179.81 & 193.21 \\
$\mathrm{PO}_{4}{ }^{3-}$ & 6.540 & 5.780 & 7.900 \\
$\mathrm{NH}_{4}{ }^{+}$ & 66.470 & 53.900 & 55.550 \\
$\mathrm{SO}_{4}{ }^{2-}$ & 35.310 & 46.560 & 32.990 \\
$\mathrm{Na}^{+}$ & 65.030 & 60.830 & 59.550 \\
$\mathrm{~K}^{+}$ & 79.580 & 75.700 & 73.99 \\
$\mathrm{Ca}^{2+}$ & 11.440 & 8.580 & 3.330 \\
$\mathrm{NO}_{3}{ }^{-}$ & 25.590 & 19.980 & 11.780 \\
\hline
\end{tabular}

\section{CONCLUSION}

The aim of this study was to synthesize struvite from different magnesium sources and assess the quality. The results indicate that the magnesium sources used are efficient for nutrient recovery. The results show how the dosage and type of magnesium source affect the precipitate yield and the nutrient recovery. It was observed that the yield is dosage sensitive, an increase if the $\mathrm{Mg} / \mathrm{P}$ ratio increases. An increased magnesium dosage (1.2:1 Mg/P ratio), increases the recovery of ammonia by $>5 \%$ compared to when the ratio was $1: 1$. Phosphorus recovery was not affected significantly, the recovery was decreased by $<2 \%$, this applies to both magnesium sources. To maximize the removal of both nutrients, the $1.2: 1$ ratio should be used.

\section{ACKNOWLEDGEMENT}

Author EFK acknowledged the financial support from the National Research Foundation (NRF) in South Africa (Grant No: 120323); Any opinion, findings and conclusions or recommendations expressed in this material are those of the authors and therefore the NRF does not accept any liability in regard thereto.

\section{REFERENCES}

[1] Kataki S., Baruah D.C. (2018) Prospects and Issues of Phosphorus Recovery as Struvite from Waste Streams. In: Hussain C. (eds) Handbook of Environmental Materials Management. Springer, Cham. https://doi.org/10.1007/978-3-319-58538-3_19-1

[2] Liu, B., Giannis, A., Zhang, J., Chang, V. and Wang, J., 2013. Characterization of induced struvite formation from source-separated urine using seawater and brine as magnesium sources. Chemosphere, 93(11), pp.2738-2747. https://doi.org/10.1016/j.chemosphere.2013.09.025

[3] Rahman, M., Salleh, M., Rashid, U., Ahsan, A., Hossain, M. and Ra, C., 2014. Production of slow release crystal fertilizer from wastewaters through struvite crystallization - A review. Arabian Journal of Chemistry, 7(1), pp.139-155. https://doi.org/10.1016/j.arabjc.2013.10.007

[4] Zeng, F., Zhao, Q., Jin, W., Liu, Y., Wang, K. and Lee, D. (2018). Struvite precipitation from anaerobic sludge supernatant and mixed fresh/stale human urine. Chemical Engineering Journal, 344, pp.254-261 https://doi.org/10.1016/j.cej.2018.03.088

[5] Shaddel, S., Ucar, S., Andreassen, J. and Østerhus, S., 2019. Engineering of struvite crystals by regulating supersaturation - Correlation with phosphorus recovery, crystal morphology and process efficiency. Journal of Environmental Chemical Engineering, 7(1), p.102918. https://doi.org/10.1016/j.jece.2019.102918

[6] Kumari, S., Jose, S., Tyagi, M. and Jagadevan, S. (2020). A holistic and sustainable approach for recovery of phosphorus via struvite crystallization from synthetic distillery wastewater. Journal of Cleaner Production, 254, p.120037. https://doi.org/10.1016/j.jclepro.2020.120037

[7] E. Mamakoa, E. Fosso-Kankeu*, V. Masindi and HWJP. Neomagus. 2019. Sources of magnesium used in the synthesis of struvite from wastewater: A Review. Editors: Elvis Fosso-Kankeu, Frans Waansders, Hemant Kumar Bulsara. $17^{\text {th }}$ Johannesburg International Conference on Science, Engineering, Technology and Waste Management (SETWM-19) Nov. 18-19, 2019 Johannesburg (South Africa). ISBN-978-81-943403-0-0. Vol. I. Pp 75-78.

[8] Fattah, K. and Mavinic, D. (2013). Investigating techniques to determine magnesium addition requirements for the operation of a struvite crystallization process. International Journal of Environmental Science and Technology, 12(2), pp.473-478. https://doi.org/10.1007/s13762-013-0448-0

[9] Etter, B., Tilley, E., Khadka, R. and Udert, K., 2011. Low-cost struvite production using source-separated urine in Nepal. Water Research, 45(2), pp.852-862.

https://doi.org/10.1016/j.watres.2010.10.007 